Epidemiology and Psychiatric

Sciences

cambridge.org/eps

\section{Editorial}

Cite this article: Ford T (2020). Transitional care for young adults with ADHD: transforming potential upheaval into smooth progression. Epidemiology and Psychiatric Sciences 29, e87, 1-5. https://doi.org/10.1017/ S2045796019000817

Received: 13 November 2019 Accepted: 14 November 2019

Key words:

Access to treatment; ADHD; service organisation; transition

Author for correspondence:

Tamsin Ford, E-mail: tjf52@medschl.cam.ac.uk

\title{
Transitional care for young adults with ADHD: transforming potential upheaval into smooth progression
}

\section{Tamsin Ford (D)}

Department of Psychiatry, University of Cambridge, Douglas House, 18B Trumpington Road Cambridge CB2 2AH, Exeter, UK

\begin{abstract}
Increasing numbers of young adults need continued support for their attention deficit hyperactivity disorder (ADHD) beyond the age-boundary for children's services. The sparse literature on transition in general suggests patchy provision and huge gaps in transitional care, but also that young people with ADHD and other neurodevelopmental disorders fair particularly badly. Transition in health care coincides with many other important life-transitions while the difficulties associated with ADHD may make these challenges particularly hard to cope with. Parents or other advocates therefore often need to be involved, which can present problems in adult mental health services given that they tend to be less family oriented than children's services. Importantly, young people need help negotiating the transition from passive recipient of care to active self-management, and in building relationships with the adult team.

In addition to patchy provision of adult ADHD services, transition is currently hampered by poor understanding of $\mathrm{ADHD}$ as a long term condition and uncertain knowledge of what services are available among young people and parents as well as the clinicians working with them. Guidelines recommend, and more importantly young people want, access to psychosocial interventions as well as medication. However, available evidence suggests poor quality transitional care and adult services that are highly focused on medication.

Adult ADHD services need to undergo similar development to that experienced by Child and Adolescent Mental Health Services and community paediatrics over the last few decades. While we debate the relative merits of dedicated or specialist $v$. generic adult mental health services, for young adults with ADHD the training, experience and availability of professionals are more important than their qualifications or setting.
\end{abstract}

Attention deficit hyperactivity disorder (ADHD) is a common reason for attendance at Child and Adolescent Mental Health Services (CAMHS) or community paediatrics (Ford et al., 2007). A meta-analysis of 41 population-based mental health surveys of children under the age of 18 years $(n-87742)$ estimated the prevalence to lie between 2.6 and $4.5 \%$ (Polanczyk et al., 2015). A varying but small proportion of these children access services (Ford et al., 2007), but rates of clinical diagnosis and prescriptions for stimulant medication in childhood have steadily increased during the last 40 years in many parts of the world as a result of better recognition and improved service provision (Coghill, 2017). While initially conceptualised as a disorder of childhood, $15 \%$ of those affected during childhood continue to meet full diagnostic criteria for ADHD into their mid-twenties, and a further $50 \%$ continue to struggle with impairment due to sub-clinical symptoms (Faraone et al., 2006). The result is an expanding cohort of young adults who need access to treatment.

The sparse literature on transition between child and adult mental health services in general suggests that it is 'poorly planned, poorly executed and poorly experienced' (Singh et al., 2010; Signorini et al., 2018; Appleton et al., 2019). Evidence suggests that those with neurodevelopmental conditions, such as ADHD are particularly likely not to transfer to adult services (Singh et al., 2010; Buitelaar, 2017; Tatlow-Golden et al., 2018; Appleton et al., 2019). A little more than a decade after the need was formally recognised, this editorial describes what we know about transitional care among young adults with ADHD to identify progress and gaps (Nutt et al., 2007).

(c) The Author(s) 2020. This is an Open Access article, distributed under the terms of the Creative Commons Attribution licence (http:// creativecommons.org/licenses/by/4.0/), which permits unrestricted re-use, distribution, and reproduction in any medium, provided the original work is properly cited.

\section{CAMBRIDGE UNIVERSITY PRESS}

\section{Transition is a process}

Adolescence involves major developmental changes and challenges, while transitions, even if ultimately positive, require a period of adaptation. Within the context of healthcare, the consensus is that transition should extend beyond the simple transfer of clinical responsibility with an aim to support a young person into a new life-stage in a way that optimises their health and function (Beresford, 2004). The timing of the transfer between child and adult services often coincides with other major life transitions, such as leaving education, starting work or moving 
out of the parental home (Cleverley et al., 2018). Thus, young adults may be deprived of familiar support networks while facing increasing demands in several domains simultaneously (Singh et al., 2010; Signorini et al., 2018). The constellation of difficulties that comprises ADHD may be particularly salient to transition; reduced ability to organise and regulate the self, as well as the high levels of comorbidity seen in clinical populations makes coping with these changes especially challenging, while impaired function during this critical and rapid developmental period is particularly detrimental to health, educational, occupation and social outcomes (Young et al., 2016; Buitelaar, 2017; Janssens et al., in submission). National registry studies suggest that continued ADHD medication into early adulthood is associated with substantially reduced levels of suicidal behaviour (Chen et al., 2014), depression (Chang et al., 2016), substance misuse (Chang et al., 2014), road traffic accidents (Chang et al., 2017), convictions and violent reoffending (Lichtenstein and Larsson, 2013). Transitional care for the graduates of children's services with $\mathrm{ADHD}$ and ongoing clinical need is, therefore, extremely important.

At its simplest, optimum transition has been characterised by planning, information transfer between the referring and receiving teams, joint working and most importantly, continuity of care (Royal College of Paediatric and Child Health, 2003; Singh et al., 2010; NICE, 2016). There has been surprising little research on the outcomes of transition in general (and ADHD in particular), but a recent scoping review identified six core components that could be used to evaluate interventions to support transition (Cleverley et al., 2018). These were transitional policy, tracking and monitoring, transition readiness, transition planning, transfer of care and completion of transfer. Similarly, a systematic review of transition for young people with various long term conditions in paediatric services suggested that preparation should commence in early adolescence but outcomes were better if transition was completed later, with 18 years recommended as the ideal age (Yassee et al., 2019).

There are some common barriers to the transition process in health care, some of which are relatively simple to address. A systematic review of transition from paediatric to adult care across varied conditions in the United States of America identified the following issues; changing relationships, accessing adult practitioners, gaining funding, negative beliefs about adult care, lack of knowledge about the transition process and lack of selfmanagement skills (Gray et al., 2018). Similarly, a follow up study of young people in the UK with diabetes, cerebral palsy or autistic spectrum conditions found appropriate parent involvement, promotion of health self-efficacy and meeting the adult team before transfer were strongly associated with better outcomes (Colver et al., 2018). Parental involvement was also a predictor of successful transition from CAMHS to adult mental health services in the TRACK study (Singh et al., 2010). The children's services and adult services (CATCh-uS) study focused on transition in $\mathrm{ADHD}$, and included semi-structured interviews with three groups of young people (before and after transition; plus those who dropped out of children's services and re-entered adult mental health services after a year or more); as well as parents and clinicians from CAMHS, paediatrics, adult mental health services and primary care (Janssens et al., in submission). Analysis indicated the pivotal role of parents as advocates, and a need to balance the young person's participation in treatment decisions with the need to protect their interests according to their developmental capacity. Developmental capacity may be particularly likely to be out of step with chronological age given the core impairments of
ADHD (Coghill, 2017; Eke et al., 2019a). Echoing earlier work (Colver et al., 2018; Gray et al., 2018), participants in the CATCh-uS study emphasised two competing issues; how prepared the young person is for transition, and their ability to manage their ADHD themselves. Both are potential therapeutic targets, and the evidence-base would suggest that preparation should commence in early adolescence to provide time to develop selfmanagement skills (Yassee et al., 2019).

Disengagement may occur before the upper age-boundary for the service if transition is not discussed, which contrasts with current common practice in many children's services, where the literature indicates little differentiation in the approach to young children or adolescents and poor awareness of adult provision (Buitelaar, 2017; Price et al., 2018). The CATCh-uS study revealed that many young people and parents lacked understanding that ADHD may persist into adulthood as well the common perception that medication was related to coping with school (Janssens et al., in submission). These were commonly cited reasons for dropping out of healthcare and suggest a need to support young people to develop greater awareness of the impact of $A D H D$ on their lives and strategies to manage it (Buitelaar, 2017). Indeed, current guidelines would recommend reassessment at the point of transition as part of transition planning, which could prompt such discussions (Kooij et al., 2010; Young et al., 2016).

\section{ADHD and transition}

There are also condition specific barriers to transition (Colver et al., 2018; Gray et al., 2018). For ADHD these are lack of service provision, poor understanding or scepticism about $A D H D$ as a long term condition, and insufficient knowledge about the existence of adult ADHD services where these are available (Price et al., 2018; Janssens et al., in submission). In the CATCh-uS surveillance study, only $6 \%$ young adults with ADHD who needed and wanted to continue their ADHD medication experienced optimal transition at follow up; and only one fifth transferred successfully (Eke et al., 2019a). Initial referral (75\% referred, 63\% accepted) and continuity of care after referral (only $22 \%$ attended their first appointment at adult mental health services) were key weak points in the pathway, so should be targets for service improvement.

Lack of transitional service provision may lead to premature cessation of medication, inappropriate attendance by adults at children's services or discharge to primary care despite ongoing clinical need (Price et al., 2018; Tatlow-Golden et al., 2018; Janssens et al., in submission). Data from UK primary care suggest that even 5 years after national guidance recommended continued treatment for adults that require it, only $18 \%$ of young people prescribed medication for ADHD in their early teens continued to receive prescriptions beyond the age of 18 (NICE, 2008; Newlove-Delgado et al., 2019a). Of those who stopped their prescriptions, $7.6 \%$ had resumed them after the age of 20 , and resumption was associated with referral to adult mental health services (Newlove-Delgado et al., 2019b). The process of re-accessing specialist mental health services was experienced as arduous, frustrating and lengthy (Price et al., 2018; Janssens et al., in submission).

We have very limited empirical evidence about how many young people require transition in relation to their ADHD, but that we have strongly suggests considerable under-provision. Prospective reports by consultant paediatricians and child psychiatrists across the United Kingdom and Southern Ireland suggest that between 270 and 599 per $10000017-19$ year olds per 
year needed transition (Eke et al., 2019a). Given the increases in medication prescribing these figures should be expected to increase and will underestimate of the level of service provision required as inclusion in the study depended on needing and wanting continued medication. Many adults with ADHD want and could benefit from psychological support (Buitelaar, 2017; Coghill, 2017; NICE, 2018; Janssens et al., in submission) while triangulating these reports against a secondary data source suggested a high likelihood of incomplete case ascertainment (Eke et al., 2019b). These estimates should be taken as the lower limit of what is needed.

\section{What should adult ADHD services provide?}

The focus on medication to the exclusion of other types of intervention is problematic (Janssens et al., in submission). Indeed, many of the factors highlighted that promote continuity of care involve education and the promotion of self-management. While many patients would welcome psychological support, practitioners report lacking the time or resources to deliver it (Janssens et al., in submission). There is little evidence currently that psychological therapy is effective for ADHD in childhood, but relatively few robust studies have been undertaken with adolescents and adults (Buitelaar, 2017). Motivational interviewing, cognitive behavioural approaches and mindfulness-based techniques might assist young people to improve their self-awareness as well as organisational, problem solving and decision-making skills, but need empirically testing (Buitelarr, 2017). As Professor Buitelaar asserts, we might be able to engage and support young people with ADHD using smartphone apps or games, provided evaluation demonstrated their effectiveness. Programmes that tailor support to the individual and include education, occupation and social issues may be more successful than medication provision alone (Embrett et al., 2016; Coghill, 2017). They could potentially be highly cost-effective, given the high rate of ADHD reported among prison populations (Young et al., 2018).

The difference in culture between child centred services, where parental involvement is assumed, to adult oriented services where parents were not necessarily included, causes problems for young people in transition and their carers (Singh et al., 2010; Price et al., 2018; Janssens et al., in submission). If parents are highly involved in supporting their child's access to health care, their exclusion from adult mental health services may lead to disengagement by default rather than intention (Colver et al., 2018; Janssens et al., in submission). There can, however, be tensions between the needs and wishes of the young adult and those of their carers, which all stakeholders need to negotiate carefully (Singh et al., 2010; Colver et al., 2018; Janssens et al., in submission). The balance can, and indeed should, change between parent-child dyads over time, and the management of this process should, if necessary, be a therapeutic target. In addition, there is an obvious issue for services to consider in terms of advocacy for young adults without parental support, such as those leaving the care system.

\section{Service organisation and transitional care models}

Provision is strongly influenced by the historical development and funding processes (Crowley and Wolfe, 2013). Structural issues include the presence or absence of strong primary care, the availability of highly specialist centres of excellence, how specialist and primary care work together and whether primary and specialist care offer services for both adults and children, or physical and mental health. The extent to which health care is integrated with social and special educational services that many children with long term conditions need is also important (Crowley and Wolfe, 2013). The need for transition to adult services emerged with the shift from acute infections to chronic disease, while mental health services are particularly poorly resourced, and organised around episodes of care and severity (Crowley and Wolfe, 2013). There is huge variation in what is provided between and within countries, and whether the focus is restricted to 'core' mental health or broader needs (Certrano et al., 2020). Furthermore, paediatrics, CAMHS and adult mental health services are rarely all financed and administered within the same organisation, while training for professionals who work with children and adults often diverges at an early point. The resulting knowledge and cultural gaps combined with fragmentation of organisation, skills and knowledge-base as well as resources undermine collaborative working, which is essential to optimise transition (Coghill, 2017; Cortese and Barbui, 2017; Janssens et al., in submission). Stigma related to ADHD and adult mental health services may deter some young adults from transition (Young et al., 2016), which may be particularly salient for those initially treated within paediatrics as children. Indeed a lower proportion of young people transferred successfully from paediatric services than from CAMHS in the CATCh-uS surveillance study (Eke et al., 2019a). Moreover, social concerns about peers' evaluations may be particularly acute for adolescents (Buitelaar, 2017); the level of concern and considerations about stigma and disclosure should be a topic of discussion as part of transition preparation.

There have been a flurry of concerns about the provision of mental health care for young people, as well as for adolescents with long term conditions across high income countries (Crowley and Wolfe, 2013; McGorry et al., 2013). In Australia, 'Headspace' centres supplement traditional primary care for young people aged 12-25 years and offer easily accessible mental and physical health care, drug and alcohol services and access to vocational or educational advice as well as a public health remit that extends into schools and communities and includes on-line resources (McGorry et al., 2013). These centres have strong links to secondary mental health care centres that also focus on young people, particularly those with emerging severe mental illness and personality disorder. Similarly, the 'Youthspace' programme in the city of Birmingham is one of several UK-based examples of youth services that aim to provide easy access to specialist mental health care for young adults up to the age of 25 ; it includes a dedicated team for transition and specific consideration of ADHD (McGorry et al., 2013). While moving the upper age boundary to 25 avoids a break in provision at the maximal incidence for psychosis, eating disorders and personality disorder, it may merely postpone difficulties with transition for those with ADHD if the capacity of adult mental health services to work with this condition is not improved.

A systematic review identified three distinct but not mutually exclusive models of transitional care, all originating from the United States of America, as well as a lack of evidence to support their application (Nguyen et al., 2017). The framework for understanding mental health service utilisation classifies young people by their current needs and previous service use patterns to suggest a personalised approach to future care. The transition to independence model advocates for a transition worker to support individuals to plan their future care in relation to their needs. This is similar to the Transition Service Integration model, which incorporates the service context as well as individual 
needs to support future function. All models stress the need for broader services than mental health alone, and highlighted particular gaps in relation to sexuality, finance, environment and culture. We need evaluations of different models in a variety of locations to guide us as to which model is most effective in which context.

Despite the lack of evidence to support particular models of care in ADHD (Cortese and Barbui, 2017), there is much debate amongst stakeholders whether care for adults with ADHD can be adequately provided within generic adult mental health services or whether dedicated specialist services are preferable. There is also debate about what constitutes a specialist service? A Delphi study conducted about this issue in relation to eating disorders that concluded specialist services provide evidence-based interventions, must be multi-disciplinary, and staff working within the service must have a clear focus on, and expertise in, the focus condition (Petkova et al., in revision). The number of cases managed was also considered important but consensus was not achieved on how many were required to signify specialist expertise. An economic evaluation of specialist $v$. generic eating disorder services for young people suggested that specialist services did not produce better outcomes but as they worked with young people who had more severe difficulties, they were costeffective depending on willingness to pay (Byford et al., 2019). It is intuitively plausible that a combination of regional highly specialist services to provide training, consultation and direct work with those with complex difficulties could compliment more widespread support in generic adult mental health teams, but proper evaluation is as desperately needed.

Adult ADHD services need to undergo similar development to that experienced by CAMHS and community paediatrics over the last three decades (Coghill, 2017). Clinical guidelines state that the following provision should be available for adults with ADHD: transitional care, assessment and diagnostic services, drug titration, monitoring and review, and psychoeducation (Nutt et al., 2007; Kooij et al., 2010; NICE, 2016, 2018; Young et al., 2016). Yet the research literature demonstrates that service provision remains highly variable between and within different countries, and that very few of those who need ongoing care for their ADHD make the transition to adult services, let alone experience anything that approaches optimal transitional care (Coghill, 2017; Eke et al., 2019a; Janssens et al., in submission).

We should be reassured that the epidemiological evidence points to continued under-recognition and under-treatment of children and young people in many countries (Ford et al., 2007; Coghill, 2017; Wang et al., 2017; Mandalia et al., 2018). But this also means that recent increases in the number of children prescribed ADHD related medication may continue and will logically be followed by an increase in the number of young adults who should transition. Service providers and commissioners should plan accordingly. As Professor Coghill argues, the training, experience and availability of professionals are more important than their qualifications or setting, but given how complex and variable the manifestations of ADHD can be, management by primary care without the support of specialist services may miss important comorbidities, even in 'uncomplicated cases' (Coghill, 2017). What is important for young adults and their carers is access to services that understand their condition and support to them to manage it, rather than where or by whom they are seen (Janssens et al., in submission). There is a desperate need for improved transitional and adult ADHD service provision, and now clear signals from research about what would improve continuity of care into adulthood; it is up to us all to implement and evaluate them.

Acknowledgements. With thanks to all those that I have discussed transition in ADHD with. These include the participants of CATCh-uS, the research team (Astrid Janssens, Tamsin Newlove-Delgado, Anna Price, Helen Eke, Sharon Blake, Siobhan Mitchell, Simon Benham-Clarke \& Anna Stimpson), our co-applicants (Cornelius Ani, Moli Paul, Chris Hollis, Kapil Sayal, Susan Young and Phil Asherson) and the Project Steering Group led by Edmund Sonuga Barke our Parent and young people advisers.

Financial support. TF completed this work while Principal Investigator of the CATCh-uS study of transition in ADHD, which is funded by the National Institute for Health Research (NIHR) Health Service and Delivery Research (HS\&DR) Programme (project number 14/21/52), while the development work was supported by the National Institute for Health Research Collaboration for Leadership in Applied Health Research and Care South West Peninsula. These funders had no role in study design, data collection, data analysis, interpretation of data or writing of this editorial. The views and opinions expressed therein are those of the authors and do not necessarily reflect those of the NIHR HS\&DR Programme, NIHR, NHS or the Department of Health and Social Care.

Conflict of interest. TF has received research grant funding to study transition from CATCh-uS and as a co-applicant on the TRACK study (Service Delivery and Organisation, Department of Health, 08/1613/117); she was an unpaid collaborator on the iTRACk study (Health Research Board HSR/2010/27).

\section{References}

Appleton R, Connell C, Fairclough E, Toumainen H and Singh SP (2019) Outcomes of young people who reach the transition boundary of child and adolescent mental health services: a systematic review. European Child and Adolescent Psychiatry 28, 1431-1446.

Beresford B (2004) On the road to nowhere? Young disabled people and transition. Child: Care, Health and Development 30, 581-587.

Buitelaar JK (2017) Optimising treatment strategies for ADHD in adolescent to minimise "lost in transition" into adulthood. Epidemiology and Psychiatric Services 26, 448-452.

Byford S, Petkova H, Stuart R, Nicholls D, Simic M, Ford T, Macdonald G, Gowers S, Roberts S, Barrett B, Kelly J, Kelly G, Livingstone N, Joshi K, Smith H and Eisler I (2019) Alternative community-based models of care for young people with anorexia nervosa: the CostED national surveillance study. Health Services and Delivery Research 7(37).

Certrano G, Salvador-Carulla L, Tedeschi F, Rabbi L, Gutierrez-Colosia MR, Gonsalez-Caballero JL, Park AL, McDaid D, Sfetcu R, Kalseth J, Kalseth B, Hope Ø, Brunn M, Chevrue K, Strasßmayr C, Hagmair G, Wahlbeck K and Amaddeo for the REFINEMENT group (2020) The balance of adult mental health care: provision of core health versus other types of care in eight European countries. Epidemiology and Psychiatric Services 29, e6. doi: 10.1017/S2045796018000574.

Chang Z, Lichtenstein P, Halldner L, D'Onofrio B, Serlachius E, Fazel S, Långström $\mathbf{N}$ and Larsson $\mathbf{H}$ (2014) Stimulant ADHD medication and risk for substance abuse. Journal of Child Psychology, Psychiatry \& Allied Disciplines 55, 878-885.

Chang Z, D'Onofrio BM, Quinn PD, Lichtenstein P and Larsson H (2016) Medication for attention-deficit/hyperactivity disorder and risk for depression: a nationwide longitudinal cohort study. Biological Psychiatry 80, 916-922.

Chang Z, Quinn PD, Hur K, Gibbons RD, Sjolander A, Larsson H and D'Onofrio BM (2017) Association between medication use for attentiondeficit/hyperactivity disorder and risk of motor vehicle crashes. JAMA Psychiatry 74, 597-603.

Chen Q, Sjolander A, Runeson B, D'Onofrio BM, Lichtenstein P and Larsson H (2014) Drug treatment for attention-deficit/hyperactivity disorder and suicidal behaviour: register based study. British Medical Journal 348, g3769.

Cleverley K, Rowland E, Bennet K, Jeffs L and Gore D (2018) Identifying core components and indicators of successful transitions from child to adult mental health services: a scoping review. European Child and Adolescent Psychiatry. online first doi.org/10.1007/s00787-018-1213-1. 
Coghill D (2017) Organisation of services for managing ADHD. Epidemiology and Psychiatric Services 26, 453-458.

Colver A, McConachie H, Le Couteur A, Dovey-Pearce G, Mann KD, McDonagh JE, Pearse MS, Vale L, Merrick H, Parr JLR and 7 the Transition Collaborative Group (2018) A longitudinal, observational study of the features of transitional healthcare associated with better outcomes for young people with long-term conditions. BMC Medicine 16, 111.

Cortese S and Barbui C (2017) Attention-deficit/hyperactivity disorder (ADHD): from randomised controlled trials to evidence-based clinical services. Epidemiology and Psychiatric Services 26, 445-447.

Crowley R and Wolfe I (2013) Transitions from children's to adults' services. In McKee M and Wolfe I (eds), European Child Health Systems and Services; Lessons Without Borders. Berkshire: Open University Press, McGill McgrawEducation, pp. 93-112.

Eke H, Ford T, Newlove-Delgado T, Price A, Young S, Ani C, Sayal K, Lynn R, Paul M and Janssens A (2019a) Transition between child and adult services for young people with attention-deficit hyperactivity disorder (ADHD): findings from a British national surveillance study. British Journal of Psychiatry Early View, 1-7. doi: doi.org/10.1192/bjp.2019.131.

Eke H, Janssens A, Downs J, Lynn RM, Ani C and Ford T (2019b) How to measure the need for transition to adult services among young people with Attention Deficit Hyperactivity Disorder (ADHD): a comparison of surveillance versus case note review methods. BMC Medical Research Methodology 19(1), 179. doi: 10.1186/s12874-019-0820-y.

Embrett MG, Randall GE, Longo CJ, Nguyen T and Mulvale G (2016) Effectiveness of health system services and programs for youth to adult transitions in mental health care: a systematic review of academic literature. Administration, Policy and Mental Health 43, 259-269.

Faraone SV, Biederman J and Mick E (2006) The age-dependent decline of attention deficit hyperactivity disorder: a meta-analysis of follow-up studies. Psychological Medicine 36, 159-165.

Ford T, Hamilton H, Meltzer H and Goodman R (2007) Child mental health is everybody's business: the prevalence of contact with public sector services by type of disorder among British school children in a three-year period. Child and Adolescent Mental Health 12, 7.

Gray WN, Schaefer MR, Resmini-Rawlinson A and Wagoner ST (2018) Barriers to transition from pediatric to adult care: a systematic review. Journal of Pediatric Psychology 43, 488-502.

Janssens A, Eke E, Price A, Newlove Delgado T, Blake S, Ani C, Asherson P, Beresford B, Emmens T, Hollis C, Logan S, Paul M, Sayal K, Young S and Ford T (in submission) Young people with attention deficit hyperactivity disorder (ADHD) in transition from children's services to adult services (Catch-uS): a mixed methods project using national surveillance, qualitative and mapping studies. National Institute of Health Research HR\&RD Journal.

Kooij SJJ, Bejerot S, Blackwell A, Caci H, Cassas-Brugué M, Carpentier PJ, Edvinsson Dm Fayyad J, Foekin K, Fitzgerald M, Gaillac V, Ginsberg Y, Henry C, Krause J, Lensing MB, Manor I, Niederhofer H, Nunes-Filipe C, Ohlmeir MD, Oswald P, Pallanti S, Pehlivanidis A, Ramos-Quiroga JA, Rastam M, Ryffel-Rawwak D, Stes S and Asherosn P (2010) European consensus statement on the diagnosis and treatment of adult ADHD. BMC Psychiatry 10, 67.

Lichtenstein P and Larsson $\mathbf{H}$ (2013) Medication for attention deficit-hyperactivity disorder and criminality. New England Journal of Medicine 368, 776.

Mandalia D, Ford T, Hill S, Sadler K, Vizard T, Goodman A, Goodman R and McManus S (2018) Mental Health of Children and Young People in England, 2017; Services, Informal Support and Education. London: NHS Digital.

McGorry P, Bates T and Birchwood M (2013) Designing youth mental health services for the 21st century: examples from Australia, Ireland and the UK. British Journal of Psychiatry 202(S54), S30-S35.

Newlove-Delgado T, Hamilton W, Ford TJ, Stein K and Ukoumunne OC (2019a) Prescribing for young people with attention deficit hyperactivity disorder in UK primary care: analysis of data from the Clinical Practice Research Datalink. ADHD Attention Deficit and Hyperactivity Disorders 11, 255. doi: 10.1007/s12402-019-00288-6.

Newlove-Delgado T, Ford TJ, Hamilton $\mathrm{W}$, Janssen A, Stein $\mathrm{K}$ and Ukoumunne OC (2019b) Resumption of ADHD medication in early adulthood; findings from a UK primary care prescribing study. European Child and Adolescent Psychiatry 28, 1589. doi: 10.1007/s00787-019-01325-5.
Nguyen T, Embrett MG, Barr NG, Mulvale GM, Vania DK, Randall GE and DiRezzo B (2017) Preventing youth from falling down the cracks between child/adolescent and adult mental health services: a systematic review of models of care. Community Mental Health Journal 53, 375-382.

NICE (2008) Attention Deficit Hyperactivity Disorder: Diagnosis and management of ADHD in children, young people and adults (CG72). Available at http://publications.nice.org.uk/attention-deficit-hyperactivitydisorder-cg72 (Accessed 7 April 2017).

NICE (2016) Transition from children's to adults' services for young people using health or social care services (NG43). Available at http://publications.nice.org.uk/attention-deficit-hyperactivity-disorder-cg72 (Accessed 31 October 2019).

NICE (2018) Attention deficit hyperactivity disorder: diagnosis and management (NG87). Available at https://www.nice.org.uk/guidance/ng87/chapter/ Recommendations (Accessed 31 October 2019).

Nutt D, Fone K, Asheron P, Bramble D, Hill P, Matthews K, Morris KA, Santosh P, Songa-Barke E, Taylor E, Weiss M and Young S (2007) Evidence-based guidelines for the management of attention-deficit/hyperactivity disorder in adolescents in transition to adult services: recommendations from the British association of psychopharmacology. Journal of Psychopharmacology 21, 10-41.

Petkova H, Eisler I, Nicholls D, Simic M, Ford T, Kelly J, Macdonald G, Barrett B, Gowers S, Joshi K, Kelly G, Livingstone N, Oliver J, Smith H, Stuart $\mathbf{R}$ and Byford $\mathbf{S}$ (in revision) Defining specialist community eating disorders services: a Delphi survey. British Journal of Psychiatry Open.

Polanczyk GV, Salum GA, Sugaya LS, Caye A and Rohde LA (2015) Annual Research Review: a meta-analysis of the worldwide prevalence of mental disorders in children and adolescents. Journal of Child Psychology and Psychiatry 56, 345-365.

Price AM, Janssens A, Woodley AL, Allwood M and Ford T (2018) Review: experiences of healthcare transitions for young people with attention deficit hyperactivity disorder: a systematic review of qualitative research. Child and Adolescent Mental Health 24, 113-122.

Royal College of Paediatrics and Child Health (2003) Bridging the Gap Health Care for Adolescents. London: Royal College of Paediatrics and Child Health.

Signorini G, Singh SP, Marsanic VB, Dieleman G, Dodig-Ćurković K, Franic T, Gerritsen SE, Griffin J, Maras A, McNicholas F, O'Hara L, Purper-Ouakil D, Paul M, Russet F, Santosh P, Schulze U, Street C, Tremmery S, Tuomainen H, Verhulst F, Warwick J, de Girolamo G and MILESTONE Consortium (2018) The interface between child/adolescent and adult mental health services: results from a European 28-country survey. European Child \& Adolescent Psychiatry 27, 501-511. doi:10.1007/ s00787-018-1112-5.

Singh SP, Paul M, Ford T, Kramer T, Weaver T, McLaren S, Hovish K, Islam Z, Belling $\mathbf{R}$ and White $\mathbf{S}$ (2010) Process, outcome and experience of transition from child to adult mental healthcare: multi-perspective study. The British Journal of Psychiatry 197, 305-312.

Tatlow-Golden M, Gavin B, McNamara N, Singh S, Ford T, Paul M, Cullen W and McNicholas F (2018) Transitioning from child and adolescent mental health services with attention-deficit hyperactivity disorder in Ireland: case note review. Early Intervention in Psychiatry 12, 505-512.

Wang LJ, Lee SL, Yuan SS, Yang CJ, Yang KC, Huang TS, Chou WJ, Chou MC, Less MJ, Lee TL and Shyu YC (2017) Prevalence rates of youths diagnosed with and medicated for ADHD in a nationwide survey in Taiwan from 2000 to 2011. Epidemiology and Psychiatry Services 26, 624-634.

Yassee A, Hale D, Armitage A and Viner R (2019) The impact of age of transition on outcomes in the transition from pediatric to adult services; a review of reviews. Journal of Adolescent Health 624, 709-720.

Young S, Adamou M, Asherson P, Coghill D, Colley B, Gudjonsson G, Hollis C, McCarthy J, Muller U, Paul M, Pitt M and Arif M (2016) Recommendations for the transition of patients with ADHD from child to adult healthcare services: a consensus statement from the UK adult ADHD network. BMC Psychiatry 16, 301.

Young S, Gonzales RA, Fridman M, Hodgkins P, Kim K and Gudjonsson GH (2018) The economic consequences of Attention-Deficit Hyperactivity Disorder in the Scottish Prison System. BMC Psychiatry 18, 210. 